\title{
EARLY RE- LAPAROSCOPY IN SUSPECTED BILE DUCT INJURIES AFTER LAPAROSCOPIC CHOLECYSTECTOMY
}

\author{
Roshan Ghimire ${ }^{1 *}$, Dhiresh Maharjan ${ }^{1}$, Prabin Thapa $^{2}$
}

\section{Affiliation}

1. Assistant Professor, Department of General Surgery, Kathmandu Medical College and Teaching Hospital, Nepal.

2. Professor, Department of General Surgery, Kathmandu Medical College and Teaching Hospital.

\section{ARTICLE INFO}

Received : 11 February, 2021

Accepted : 22 March, 2021

Published : 15 June, 2021

(C) Authors retain copyright and grant the journal right of first publication with the work simultaneously licensed under Creative Commons Attribution License CC - BY 4.0 that allows others to share the work with an acknowledgment of the work's authorship and initial publication in this journal.

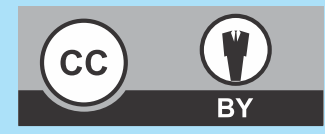

\section{ORA 242}

DOI: https://doi.org/10.3126/bjhs.v6i1.37645

\section{* Corresponding Author}

Dr Roshan Ghimire

Assistant Professor

Department of General Surgery

Kathmandu Medical College and Teaching Hospital, Nepal

Email: roshanghimire194@gmail.com

ORCID: https://orcid.org/0000-0002-9743-0458

\section{Citation}

Roshan Ghimire, Dhiresh Maharjan, Prabin Thapa. Early Re- laparoscopy in Suspected Bile Duct Injuries After Laparoscopic Cholecystectomy. BJHS 2021;6(1)14.1396-1400.

\section{ABSTRACT}

Introduction

Management of patients with suspected bile leak or bile duct injury after laparoscopic cholecystectomy is challenging. Early laparoscopy in these groups of patients will benefit in terms of diagnostic as well therapeutic purpose.

\section{Objective}

This study is done to assess utility of early re-laparoscopy in suspected bile duct injury in early postoperative period following laparoscopic cholecystectomy.

\section{Methodology}

It is a descriptive study of all consecutive patients who underwent diagnostic as well therapeutic re-laparoscopy when required in suspected bile duct injury in early postoperative laparoscopic cholecystectomy that is within 72 hours of presentation. Study was conducted over a period from June 2019 to December 2020 at Kathmandu medical College, Sinamangal, Kathmandu, Nepal. Relaparoscopic operative findings and therapeutic intervention done were recorded.

\section{Result}

The mean age at presentation was 34.6 years and male to female ratio was 1:1.8. During the study period, eleven patients underwent re-laparoscopy out of which one had no bile leak. Six out of ten were managed definitely in the same time of re-laparoscopy. However, four patients underwent definitive biliary reconstruction as they had already undergone arteriography in CT scan.

\section{Conclusions}

Early re-laparoscopy may be beneficial prior to detail radiological investigations in suspected bile leak patients. Early re-laparoscopy can be an effective diagnostic as well therapeutic tool; and also it can help in planning for definitive repair in later date.

\section{KEYWORDS}

Bile leak, laparoscopic cholecystectomy, laparoscopy 


\section{INTRODUCTION}

Laparoscopic Cholecystectomy (LC) is one of the most frequently performed procedures in gastrointestinal surgery. ${ }^{1}$ As there is widespread adoption of laparoscopic cholecystectomy, there also increases the suspicion of bile leak post operatively with classical symptoms like backache, pain abdomen and features of biliary peritonism. ${ }^{1}$ Bile duct injury after laparoscopic cholecystectomy is a major complication that can prove to be life-threatening. ${ }^{2}$ Bile duct injury is a grievous complication with high morbidity and mortality, hence it needs to be prevented, and detected early for better outcomes

In the hands of an experienced surgeon, the lifetime risk bile duct injury following laparoscopic cholecystectomy for gallbladder stones without acute inflammation has been reported to be about $0.4 \%{ }^{3}$ There is always some substantial risk of bile duct injury while performing laparoscopic cholecystectomy. ${ }^{3}$ Therefore, the need to maximize surgical safety is always overemphasized.

Various anatomical abnormalities of the biliary tract have been reported hence intra-operatively, biliary anatomy needs to be assessed with establishment of critical view of safety. Though there is still no consensus to avoid bile duct injury during LC, most surgeons agree with critical view of safety and some surgeons advocate for intraoperative cholangiogram as safety majors. ${ }^{4}$ Now-a days, Real-time intraoperative imaging using indocyanine green (ICG) is practiced to reduce the risk of bile duct injury by improving visualization of the biliary tree during laparoscopic cholecystectomy. ${ }^{4}$

Early identification of bile duct injuries following laparoscopic cholecystectomy is crucial. The prognosis depends upon timing of its recognition and type of injury. The management of patients following bile duct injury is challenging which requires skills of experienced hepato-biliary surgeons with good collaboration with various disciplines.

The aim of the treatment of bile duct injury is immediate management of the associated sepsis, fistula and obstruction of the biliary system primarily, sepsis, biliary leaks and collections should be managed appropriately followed by identification and categorization of the type of major bile duct injury.

The optimum management of patients with suspected bile leak or bile duct injury after laparoscopic cholecystectomy is very important. Early laparoscopy can provide diagnostic as well therapeutic management in theses group of patients with high index of suspicion.?

To improve the quality of life of laparoscopic bile duct injury patients, early detection of bile duct injuries, complete evaluation of the biliary duct, and appropriate surgical management is necessary. Early re-laparoscopy not only permits drainage of intraabdominal bile collection but also helps in detecting and controlling the site of leakage. Relying on the laparoscopic methods at later date not only improves the patients quality of life but also helps in reducing the patients morbidity. ${ }^{8}$ Hence the aim of this study was to analyze the role of early re-laparoscopy in bile leaks after laparoscopic cholecystectomy in relation to further investigation and definitive management.

\section{METHODOLOGY}

This was a descriptive study of a prospectively maintained database. The data were prospectively collected and entered into a database for analysis and included following preoperative, intraoperative, and postoperative variables. All consecutive patients who underwent diagnostic as well therapeutic early re-laparoscopy when required in suspected bile leak after laparoscopic cholecystectomy over a period from June 2019 to December 2020 at Kathmandu medical College, Sinamangal, Kathmandu, Nepal were included in the study. The same team of surgeons performed all the surgeries (re-laparoscopy and proceed). Inclusion criteria's in the study were previous laparoscopic cholecystectomy done within 72 hours with symptoms of backache, pain abdomen and/or features of peritonism along with intra-abdominal collection noted in ultrasound abdomen. Previous laparoscopic turned open surgery and referred cases with laparoscopy done for more than 72 hours were excluded from the study. Classification of bile duct injury was done with Strasberg classification followed by definitive repair of the injury.

Demographic data and results of diagnostic and therapeutic procedures before and after referral, including laboratory data and imaging studies were obtained for all patients. All patients' blood samples (complete blood count, liver function tests, kidney function tests and serum amylase) were assessed. All patients underwent ultrasonographic assessment of the abdomen and pelvis. $\mathrm{CT}$ abdomen and pelvis and/or MRI were not done routinely but were assessed only of those who already had the imaging available. Patients' variables like age; gender and indication for prior surgery were recorded. Operative data and mainly operative findings were recorded and analyzed.

It was ensured that participants were fully informed and gave their free consent to participate in the study. Ethical approval was obtained from the institutional review committee of Kathmandu Medical College public Limited, Kathmandu, Nepal. The study protocol conferred to the ethical guidelines of the 1975 declaration of Helsinki.

For quantitative data, the results were expressed as the mean +/- standard deviation (SD) and for categorical data; the results were expressed as the number and percentage of cases. Values are expressed as the means and ranges, or percentages, when appropriate. All the information collected from study population was entered in Microsoft Excel 2013 and all data were analyzed using the Statistical Package for the Social Sciences (SPSS) version 20. 


\section{RESULTS}

Over this study period (June 2019 to December 2020), 11 patients underwent diagnostic as well therapeutic relaparoscopy when required in suspected biliary peritonism or with bile leak in early postoperative laparoscopic cholecystectomy (within 72 hours).

The mean age of patients in this study was 34.6 years, with a male: female ratio of 1:1.8. (Table 1) Among study population, reason of undergoing laparoscopic cholecystectomy primarily were acute cholecystitis in two patients (18.2\%), chronic cholecysytitis in 7 patients (63.6\%), one patient had gall bladder polyp ( $9 \%$ ) and one patient had history of biliary colic (9\%). All patients underwent re-laparoscopy, umbilical port was used as a camera port and if required additional ports were placed for assessment. All patients were operated under general anaesthesia.

\begin{tabular}{l} 
Table 1. Patient Demographics, Perioperative Variables, \\
and Operative findings of Cases: \\
\begin{tabular}{|l|l|c|}
\hline S.N & Characteristics & Value \\
\hline A. & Patient Demographics (N=11) & 34.6 \\
\hline & Mean age & $1: 1.8$ \\
\hline & Sex (male: female) & $\begin{array}{c}\text { Number } \\
\text { (percentage) }\end{array}$ \\
\hline B. & Perioperative variables & $3(27.3 \%)$ \\
\hline & $\begin{array}{l}\text { Features of peritonitis with collection in abdomen } \\
\text { noted in ultrasound abdomen }\end{array}$ & $4(36.4 \%)$ \\
\hline & $\begin{array}{l}\text { Pain abdomen and back pain with minimal } \\
\text { abdominal collection in ultrasound }\end{array}$ & $2(18.2 \%)$ \\
\hline & $\begin{array}{l}\text { Pain abdomen and back pain with significant } \\
\text { abdominal collection in ultrasound }\end{array}$ & $2(18.2 \%)$ \\
\hline & Biliary content in drain with pain abdomen & Number \\
\hline C. & Operative findings: & $3(27.3 \%)$ \\
\hline 1. & Bile leak from Duct of luschka & $1(9.0 \%)$ \\
\hline 2. & $\begin{array}{l}\text { Cystic duct necrosis and slippage of clip } \\
\text { (clip applied region) }\end{array}$ & $2(18.2 \%)$ \\
\hline 3. & Right posterior hepatic duct linear tear & $4(36.4 \%)$ \\
\hline 4. & Major bile duct injury & 2 \\
\hline I. & Major bile duct injury without vascular & $1(9.0 \%)$ \\
\hline II. & Major bile duct injury with vascular & $\begin{array}{l}\text { Mild hemorrhagic collection (negative } \\
\text { laparoscopy) }\end{array}$ \\
\hline & & \\
\hline 5 & (percentage)
\end{tabular} \\
\hline
\end{tabular}

Among them, Five patients were referred cases, all of which had undergone CT abdomen and consequently underwent re-laparoscopy. One of them had leak from Duct of luschka, which was clipped and managed. Four of them had major bile duct injuries requiring Roux en y Hepaticojejunostomy. Two amongst them had vascular injury as well. One patient had right hepatic artery injured and next had right posterior hepatic artery injured but hepatic ischemia was none apparent hence undergone biliary reconstruction only.

Among the remaining six patients, one had cystic duct clip slippage noted on postoperative day two which was managed with re-clippling of cystic duct at the junction. Two patients had right posterior hepatic duct linear tear, which was successfully repaired laparoscopically. Another one patient had classical symptoms of bile leak and features suggestive of intra-abdominal collection in ultrasonography of the abdomen, but on re-laparoscopy minimal hemorrhagic fluid in gall bladder fossa was found. No mortality in the series was found.

In our institution, total of 511 patients underwent laparoscopic cholecystectomy for various indications over the study period. Five $(0.9 \%)$ patients had bile leak which was managed laparoscopically in the same hospital admission.

\section{DISCUSSION}

In our study, out of the eleven enrolled patients, one had negative re-laparoscopy. The re-laparoscopy for six out of the remaining ten was proven to be not only diagnostic but also therapeutic. These six patients were managed laparoscopically with lavage, drain placement and definitive repair if required.

Bile duct injury is rare, with an incidence of $0.3 \%$ to $0.7 \%$ and is mostly a result of misperception and misinterpretation of the biliary anatomy. Though, bile duct injury is rare it can lead to dreaded complications. ${ }^{8}$

The most important and common cause of bile duct injury is the failure to recognize the anatomy of the triangle of Calot. Local anatomical abnormalities as well as the laparoscopic "learning curve" of the surgeon are the most important factors related to bile duct injury. ${ }^{9}$

The local anatomical risk factors are important such as acute cholecystitis, severe chronic scarring of the gallbladder, and bleeding or excessive fat in the hepatic hilum .These factors need to be handled gently by surgical expertise to prevent bile duct injury. ${ }^{10}$

The critical view of safety and dissection within the triangle of calot constitute the most commonly employed means of preventing or reducing bile duct injury during laparoscopic cholecystectomy. Some surgeons also practice intraoperative cholangiogram in difficult cases to help delineate anatomical structures. However, new imaging modalities like real-time intra operative imaging, near-infrared fluorescent cholangiography (NIFC) using indocyanine green (ICG) can be utilized in difficult cases where the anatomy is unclear for obtaining the good critical view of safety. ${ }^{11-13}$

The optimal timing to do biliary repair has not been clearly established. Once bile duct injuries are recognized earlier, immediate management can be done with the surgical expertise. The ease of management, operative risk, and outcome of bile duct injuries vary considerably, and are highly dependent on the type of injury and its location. ${ }^{12}$

During early postoperative period when there is suspicion of bile leak or bile duct injury, laparoscopy is considered as a diagnostic as well as therapeutic approach. ${ }^{7}$ While performing laparoscopy, thorough peritoneal lavage followed by identification of bile leak site can be performed. Small leak from luschka or other sources can be managed with laparoscopy at the same time. With the help of lavage and proper placement of drain, sepsis can be controlled. ${ }^{13,14}$ 
Some leaks from the bile duct can be managed with Endoscopic retrograde cholangiopancreatography and sphincterotomy, with or without biliary stenting. But leaks from cystic duct stump, duct of luscka and small accessory bile ducts can be managed with re clipping or suturing during laparoscopy. ${ }^{7,15}$ During laparoscopy, reassessment of the anatomy must be done then judicial thinking regarding definitive repair, only placement of drain or referral of patient to hepatobiliary surgeon should be made. Mere placement of drain can also prevent from sepsis and can buy time for radiological assessment and referral for definitive repair. In our series, four referred patients had major biliary injury and these entire patients had abdominal drain placed in first surgery. These four referred patients had undergone CT Scan of the abdomen at the time of presentation to our hospital. Hence, they underwent early re-laparoscopy followed by definitive repair. The utility of re-laparoscopy among these patients was to assess condition of liver, vasculobiliary status and bowel so that definitive surgery can be performed through subcostal incision.

After a suspicious bile duct injury post cholecystectomy, relaproscopy can not only help to perform definitive repair immediately but also to plan the required procedure at a later date. ${ }^{16}$ Right hepatic artery (RHA) vasculobilary injury is the most common vasculobiliary injury during cholecystectomy(12\%). ${ }^{17,18}$ Ischemic atrophy induced by RHA injury are usually mild symptomatic or asymptomatic which can be managed on follow-up. ${ }^{19,20}$ Only around 10 percent of patients with RHA injury develop clinically relevant hepatic ischemia. $^{20,21}$

Injury to RHA is usually too severe to repair and due to delay in recognition the repair of RHA is not possible usually. In our series, two patients had vascular injury, which had nonapparent hepatic ischemia on imaging as well peroperatively, hence only biliary reconstruction was performed.

In referred cases, where video recording of primary surgery is not available, re-laparoscopy can be used to assess and plan for definitive surgery. Hence, re-laparoscopy can be kept as one of first approach in the management algorithm

\section{REFERENCES}

1. Ahmad F, Saunders RN, Lloyd GM, Lloyd DM, Robertson GS. An algorithm for the management of bile leak following laparoscopic cholecystectomy. Ann R Coll Surg Engl. 2007;89(1):51-56. doi: 10.1308/003588407X160864

2. Hariharan D, Psaltis E, Scholefield JH, Lobo DN. Quality of life and medico-legal implications following iatrogenic bile duct injuries. World J Surg 2017; 41;90-99. doi: 10.1007/s00268-016-3677-9.

3. Nuzzo G, Giuliante F, Giovannini I et al. Bile duct injury during laparoscopic cholecystectomy: results of an Italian national survey on 56591 cholecystectomies. Arch Surg. 2005;140 (10): 986-92. doi: 10.1001/archsurg.140.10.986 in bile leaks or bile duct injury during laparoscopic cholecystectomy. And also interdisciplinary cooperation and early referral to an experienced center is crucial in the management of suspected bile duct injuries patients.

\section{CONCLUSION}

The risk of bile duct injury in laparoscopic cholecystectomy has been a major concern these days as the procedure has become part of the surgical armamentarium. Our study assessed the effectiveness of early re-laparoscopy among suspected bile duct injuries cases. Early re-laparoscopy can be the foremost step in the management algorithm of suspected post cholecystectomy bile duct injuries. It can definitely aid to identify bile duct injury, even helps in early management by placement of drain and lavage; and also plan for a definitive repair to be undertaken immediately or at a later date. Hence early re- laparoscopy can be a safe and effective modality in patients with suspected bile duct injuries post laparoscopic cholecystectomy..

\section{LIMITATIONS OF THE STUDY}

This study had limitations, including a small number of patients and data from only a single center. Thus, more studies from multiple centers are needed to support our conclusions.

\section{ACKNOWLEDGEMENTS}

We would like to acknowledge Dr. Suman Shrestha, Dr. Anuj Parajuli, our other colleagues, juniors, all the staffs of Surgery department and department of anesthesiology and critical care of Kathmandu Medical College who are constantly supporting us. We are also grateful to our patients for trusting us and participitatiang in the study.

\section{CONFLICT OF INTEREST}

None

\section{FINANCIAL DISCLOSURE}

None

4. Buddingh KT, Nieuwenhuijs VB, van Buuren L, Hulscher JBF, de Jong JS, van Dam GM. Intraoperative assessment of biliary anatomy for prevention of bile duct injury: a review of current and future patient safety interventions. SurgEndosc. 2011;25:2449-2461. https:// doi.org/10.1007/s00464-011-1639-8 PMid:21487883

5. Branum G, Schmitt C, Baillie J, Suhocki P, Baker M, Davidoff A, Branch S, Chari R, Cucchiaro G, Murray E, Pappas T, Cotton P, Meyers WC. Management of major biliary complications after laparoscopic cholecystectomy. Ann Surg. 1993, 217: 532-541. 10.1097/00000658 199305010-00014.https://doi.org/10.1097/00000658-19930501000014 PMid:8489316

6. Rauws EA, Gouma DJ: Endoscopic and surgical management of bile duct injury after laparoscopic cholecystectomy. Best Pract Res Clin Gastroenterol. 2004, 18: 829-846.https://doi.org/10.1016/ S1521$6918(04) 00061-7$ 
7. Wills $\mathrm{VL}$, Jorgensen JO, Hunt DR. Role of relaparoscopy in the management of minor bile leakage after laparoscopic cholecystectomy. Br J Surg. 2000;87:176-80. https://doi.org/ 10.1046/j.1365-2168. 2000.01323.PMid:10671923

8. Barband AR, Jorgensen JO, Hunt JR, et al. Relaparoscopy in minor bile leakage after laparoscopic cholecystectomy: An alternative approach?. SurgLaparoscEndoscPercutan Tech. 2011;21:288-91. https://doi.org/10.1097/SLE.0b013e31822a2373 PMid:21857482

9. H. J. Asbun, R. L. Rossi, J. A. Lowell, J. L. Munson, and J. G. Hunter, "Bile duct injury during laparoscopic cholecystectomy: mechanism of injury, prevention, and management," World Journal of Surgery, vol. 17, no. 4, pp. 547-552, 1993.

10. Stewart, L. W. Way, and W. C. Meyers, "Bile duct injuries during laparoscopic cholecystectomy: factors that influence the results of treatment," Archives of Surgery, vol. 130, no. 10, pp. 1123-1129, 1995.

11. Osayi SN, Wendling MR, Drosdeck JM, Chaudhry UI, Perry KA, Noria SF, Mikami DJ, Needleman BJ, Muscarella P 2nd, Abdel-Rasoul M, et al. Near-infrared fluorescent cholangiography facilitates identification of biliary anatomy during laparoscopic cholecystectomy. Surg Endosc. 2015;29(2):368-75.

12. Ibrarullah M, Sankar S, Sreenivasan K, Gavini SR. Management of Bile Duct Injury at Various Stages of Presentation: Experience from a Tertiary Care Centre. Indian J Surg. 2015;77(2):92-98. doi:10.1007/ s12262-012-0722-2

13. Ishizawa $\mathrm{T}$, Bandai $\mathrm{Y}$, Ijichi $\mathrm{M}$, et al. Fluorescent cholangiography illuminating the biliary tree during laparoscopic cholecystectomy. $\mathrm{Br}$ J Surg 2010;97:1369-77.
14. Azagra JS, De Simone P, Goergen M. Is there a place for laparoscopy in management of postcholecystectomy biliary injuries? World J Surg. 2001;25:1331-4.https://doi.org/10.1007/s00268-001-0119-z PMid:11596899

15. Lo Nigro C, Geraci G, Sciuto A, et al. Bile leaks after video laparoscopic cholecystectomy: duct of Luschka. Endoscopic treatment in a single centre and brief literature review on current management. Ann ItalChir. 2012;83:303-12. [PubMed] [Google Scholar]

16. Gupta V, Jayaraman S. Role for laparoscopy in the management of bile duct injuries. Can J Surg. 2017 Oct; 60(5): 300-304. https://doi. org/10.1503/cjs.003317 PMid:28930036 PMCid:PMC5608577

17. Deziel DJ, Millikan KW, Economou SG, Doolas A, Ko ST, Airan MC. Complications of laparoscopic cholecystectomy: a national survey of 4292 hospitals and an analysis of 77604 cases. Am J Surg. 1993;165:9-14. https://doi.org/10.1016/S0002-9610(05)80397-6

18. Stewart L, Robinson TN, Lee CM, Liu K, Whang K, Way LW, et al. Right hepatic artery injury associated with laparoscopic bile duct injury: incidence, mechanism, and consequences. J Gastrointest Surg. 2004;8:523-530. [PubMed] [Google Scholar]

19. Mathisen O, Soreide O, Bergan A. Laparoscopic cholecystectomy: bile duct and vascular injuries: management and outcome. Scand J Gastroenterol. 2002;37:476-481 https://doi.org/10.1080/00365520 2317316123 PMid:11989840

20. Strasberg SM, Helton WS. An analytical review of vasculobiliary injury in laparoscopic and open cholecystectomy. HPB (Oxford). 2011 Jan; 13(1): 1-14. https://doi.org/10.1111/j.1477-2574.2010.00225. PMID: 21159098

21. Li J, Frilling A, Nadalin S, Paul A, Malago M, Broelsch CE. Management of concomitant hepatic artery injury in patients with iatrogenic major bile duct injury after laparoscopic cholecystectomy. Br J Surg. 2008;95:460-465. https://doi.org/10.1002/bjs.6022 PMID: 18161898 